\title{
Sistem Informasi Kampus Di STMIK AUB Surakarta
}

\author{
${\text { Sutariyani*1, }{ }^{\text {Paryanta }}{ }^{2} \text {, David Tjandra Akhir }}^{3}$ \\ ${ }^{1,3}$ Program Studi Sistem Informasi, STMIK AUB, Surakarta, Indonesia \\ ${ }^{2}$ Program Studi Teknik Komputer, STMIK AUB, Surakarta, Indonesia \\ e-mail: *1 tari.yani@stmik-aub.ac.id, ${ }^{2}$ paryanta@stmik-aub.ac.id, ${ }^{3}$ david.tjandra@gmail.com
}

\begin{abstract}
Abstrak
STMIK AUB Surakarta memberikan informasi kepada mahasiswa melalui dua cara yaitu melalui website dan dengan memasang pengumuman pada papan pengumuman tanpa ada pemberitahuan terlebih dahulu. Hal ini sering kali membuat mahasiswa mengalami keterlambatan dalam mendapatkan informasi terbaru. Tujuan penelitian ini adalah untuk merancang dan membangun sistem informasi kampus pada STMIK AUB Surakarta. Dalam merancang dan membangun sistem, metode pendekatan yang digunakan adalah metode waterfall. Metode pengumpulan data yang digunakan yaitu metode wawancara, metode observasi dan metode literatur. Sebagai alat analisis dan desain sistem yaitu flowchart, UML (Unified Moddeling Languange), dan ERD (Entity Relationship Diagram). Sedangkan bahasa pemrograman yang digunakan adalah Android Studio versi 3.0.1, PHP, Java, dan MySQL sebagai database. Hasil dari penelitian ini adalah membuat aplikasi sistem informasi kampus berbasis Android dengan sistem notifikasi yang dapat membantu memberikan informasi terbaru dengan cepat dan dapat diterima secara langsung oleh mahasiswa ataupun dosen STMIK AUB Surakarta.
\end{abstract}

Kata kunci: Sistem informasi, Notifikasi, Android

\section{PENDAHULUAN}

Sistem informasi adalah sekumpulan elemen yang bekerja secara bersama-sama baik secara manual maupun berbasis komputer dalam melaksanaakan pengolahan data. Proses yang dilakukan data berupa pengumpulan, penyimpanan dan pemrosesan data untuk menghasilkan informasi yang bermakna dan berguna sebagai bahan pertimbangan proses pengambilan keputusan, (Setiabudi dkk, 2012). Sistem informasi kampus merupakan bagian terpenting dalam sebuah perguruan tinggi. Sistem informasi kampus ini dibangun bagi kebutuhan perguruan tinggi akan pengelolaan data dan informasi kampus melalui teknologi informasi untuk memudahkan institusi perguruan tinggi, mahasiswa dan dosen memperoleh informasi yang akurat dan cepat tentang perkembangan perguruan tinggi tersebut.

Saat ini dosen dan mahasiswa dapat mengakses informasi yang ada di STMIK AUB Surakarta melalui website STMIK AUB. Proses yang dilakukan dosen dan mahasiswa untuk mendapatkan informasi mengenai kampus STMIK AUB yaitu dengan cara mengunjungi alamat website: www.stmik-aub.ac.id atau dengan datang ke kampus dan melihat informasi di papan pengumuman yang tersedia dibeberapa sudut kampus.

Sistem informasi yang ada saat ini memiliki kelemahan yaitu mahasiswa sering terlambat dalam mendapatkan informasi dari kampus karena mahasiswa jarang membuka website STMIK AUB. Selain itu, website tersebut hanya dapat memberikan informasi saja tanpa ada notifikasi atau pemberitahuan bahwa ada informasi terbaru mengenai kampus sehingga mahasiswa tidak mendapatkan berita secara up to date. Kelemahan lain yang dihadapi

Received May 3, 2018; Revised May 25, 2018; Accepted June 10, 2018 
mahasiswa yaitu dalam mendapatkan informasi terbaru mengenai kalender akademik dan jadwal yang meliputi: jadwal mata kuliah, jadwal UTS dan UAS, bahkan jadwal ujian skripsi pun sulit untuk didapat melalui website tersebut. Selain itu, hanya ada beberapa dosen yang membagikan materi melalui website, sehingga membuat mahasiswa kesulitan mendapatkan materi kuliah.

Dari latar belakang masalah yang ada maka penulis mengembangkan sistem informasi kampus berbasis android. Android itu sendiri merupakan sebuah sistem operasi untuk perangkat mobile berbasis linux yang mencakup sistem operasi, middleware dan aplikasi. Android menyediakan platform terbuka bagi para pengembang untuk menciptakan aplikasi mereka (Murtiwiyati, 2013). Android juga didukung dengan sistem notifikasi, sehingga sangat mungkin untuk membuat sistem informasi berbasis android dengan notifikasi.

Android yang peneliti kembangkan dapat menampilkan informasi seputar kampus, agenda kegiatan, jadwal perkuliahan, dan materi perkuliahan. Sistem informasi kampus berbasis android ini juga didukung dengan adanya sistem notifikasi sehingga informasi terbaru dapat diterima atau diketahui secara langsung oleh mahasiswa maupun dosen dengan mengaksesnya secara online melalui handphone android. Selain itu dosen dapat mengunggah materi perkuliahan, sehingga mahasiswa dapat mengunduh materi perkuliahan. Maka dapat dirumuskan masalah yaitu "Bagaimana merancang dan membangun Sistem Informasi Kampus di STMIK AUB Surakarta?" dan terbatas pada menampilkan informasi berita kampus yang berisi beritaberita seputar kampus dan yang berhubungan dengan informasi umum terbaru yang didalamnya terdapat deskripsi berita tersebut, menampilkan informasi agenda kegiatan yang akan diadakan oleh kampus yang terdapat deskripsi kegiatan dan keterangan tanggal pelaksanaan, menampilkan informasi jadwal kuliah, jadwal ujian skripsi, jadwal kkn, dan jadwal UAS/UTS yang dapat diunduh, serta terdapat informasi materi kuliah yang dapat diunduh, pembuatan Sistem Informasi Kampus Di STMIK AUB Surakarta menggunakan Android Studio.

\section{METODE PENELITIAN}

Berikut adalah metode-metode yang digunakan dalam pembuatan Sistem Informasi Kampus Berbasis Android ini adalah :

\subsection{Metode Pengumpulan Data}

\section{Metode Observasi}

Metode observasi merupakan pengamatan dapat dicek dan dikontrol atas validitas dan reliabilitasnya, (Rahayu, 2007). Metode ini dilakukan untuk mengetahui keadaan lapangan, dalam hal ini yaitu mencari informasi tentang web resmi STMIK AUB Surakarta serta mencari informasi pada bagian akademik.

2. Metode Wawancara

Metode wawancara adalah proses pengumpulan data untuk penelitian dengan cara tanya jawab sambil bertatap muka antara pewawancara dan responden, (Rahayu, 2007). Penulis melakukan wawancara dengan melakukan tanya jawab terhadap bagian akademik sehingga mendapatkan data mengenai sistem informasi kampus.

3. Metode Pustaka

Metode ini dilakukan dengan cara membaca atau mempelajari buku referensi literature yang berhubungan dengan masalah yang akan dibahas guna memperoleh landasan teori untuk keperluan menganalisa data, (Usman, 2000). Penulis mencari buku atau jurnal sebagai bahan referensi dan sebagai acuan dalam penulisan laporan serta dalam pembuatan aplikasi ini.

\subsection{Metode Pengembangan Sistem}

Pengembangan aplikasi ini menggunakan metode waterfall. Metode air terjun atau yang sering disebut metode waterfall sering dinamakan siklus hidup klasik (classic life cycle), dimana hal ini menggambarkan pendekatan sistematis dan berurutan pada pengembangan perangkat lunak, dimulai dengan spesifikasi kebutuhan pengguna lalu berlanjut melalui tahapan-tahapan perencanaan (planning), permodelan (modeling), konstruksi (construction), serta penyerahan

GO INFOTECH: JURNAL ILMIAH STMIK AUB Vol. 24, No. 1, Juni 2018 : 1 - 11 
sistem ke para pelanggan/pengguna (deployment), yang diakhiri dengan dukungan pada perangkat lunak lengkap yang dihasilkan (Pressman, 2012).

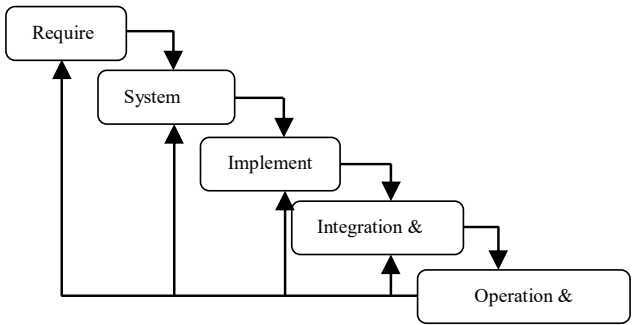

Gambar 1 Tahapan Pengembangan Metode Waterfall

Dalam pengembangannya metode waterfall memiliki beberapa tahapan yang berurut yaitu: requirement (analisis kebutuhan), design system (desain sistem), coding (pengkodean) \& testing (pengujian), penerapan program, pemeliharaan. Tahapan-tahapan dari metode waterfall adalah sebagai berikut :

1. Requirement

Tahap ini pengembang sistem diperlukan komunikasi yang bertujuan untuk memahami perangkat lunak yang diharapkan oleh pengguna dan batasan perangkat lunak tersebut. Informasi ini biasanya dapat diperoleh melalui wawancara, diskusi atau survei langsung. Informasi dianalisis untuk mendapatkan data yang dibutuhkan oleh pengguna.

2. System Design

Desain Sistem membantu dalam menentukan perangkat keras (hardware) dan sistem persyaratan dan juga membantu dalam mendefinisikan arsitektur sistem secara keseluruhan.

3. Implementation

Pada tahap ini, sistem pertama kali dikembangkan di program kecil yang disebut unit, yang terintegrasi dalam tahap selanjutnya. Setiap unit dikembangkan dan diuji untuk fungsionalitas yang disebut sebagai unit testing.

4. Integration \& Testing

Seluruh unit yang dikembangkan dalam tahap implementasi diintegrasikan ke dalam sistem setelah pengujian yang dilakukan masing-masing unit. Setelah integrasi seluruh sistem diuji untuk mengecek setiap kegagalan maupun kesalahan.

5. Operation \& Maintenance

Tahap akhir dalam model waterfall. Perangkat lunak yang sudah jadi, dijalankan serta dilakukan pemeliharaan. Pemeliharaan termasuk dalam memperbaiki kesalahan yang tidak ditemukan pada langkah sebelumnya.

\subsection{Metode Pengujian Black Box Testing}

Black Box Testing dilakukan dengan membuat kasus uji (skenario) yang bersifat mencoba semua fungsi dengan memakai perangkat lunak apakah sesuai dengan spesifikasi yang dibutuhkan. Kasus uji yang dibuat untuk menguji harus dibuat dengan skenario benar dan salah. Acuan yang digunakan dalam pembuatan instrumen pengujian Black Box adalah berdasarkan dari analisis kebutuhan (Khasanah, 2015).

\subsection{Analisa Sistem}

Dalam kelemahan sistem, penulis menggunakan metode analisis PIECES yang terdiri dari performance, information, control, efficiency dan service. Sebagai alat ukur untuk menganalisa kelemahan sistem diperlukan langkah untuk mengidentifikasi dan memberikan solusi terhadap kelemahan sistem yang ada, seperti berikut:

a. Perfomance (Kinerja)

Sistem informasi yang lama di kampus STMIK AUB Surakarta meskipun sudah ada website tetapi masih menggunakan media kertas, dimana informasi tersebut ditempelkan di papan informasi di setiap sudut kampus.

b. Information (Informasi) 
Informasi yang disampaikan tidak tepat waktu. Karena harus menunggu BAAK memberikan informasi atau mahasiswa yang aktif bertanya pada bagian BAAK atau dengan mengecek website.

c. Economy (Ekonomi)

Belum efisiennya sistem yang ada karena masih menggunakan cara manual untuk memberikan informasi.

d. Control (Keamanan)

Keamanan kurang karena informasi yang diberikan masih menggunakan kertas dan hanya ditempelkan di papan pengumuman.

e. Efficiency (Efisien)

Belum efisien, karena sudah ada website tapi masih dilakukan dengan manual atau dengan menempelkan informasi di papan pegumuman.

f. Service (Layanan)

Pelayanan hanya satu arah, BAAK harus menyiapkan atau mencetak informasi yang harus ditempelkan di papan pengumuman.

\subsection{Perancangan Sistem}

Perancangan sistem adalah sekumpulan aktivitas yang meggambarkan secara terperinci bagaimana sistem berjalan. Sistem Informasi Kampus Di STMIK AUB Surakarta dibuatkan gambaran flowchart agar pengguna dapat mengerti alur program. Berikut tabel 1 adalah flowchart Sistem yang dibangun:

Tabel 1. Flowchart Sistem Yang Dibangun

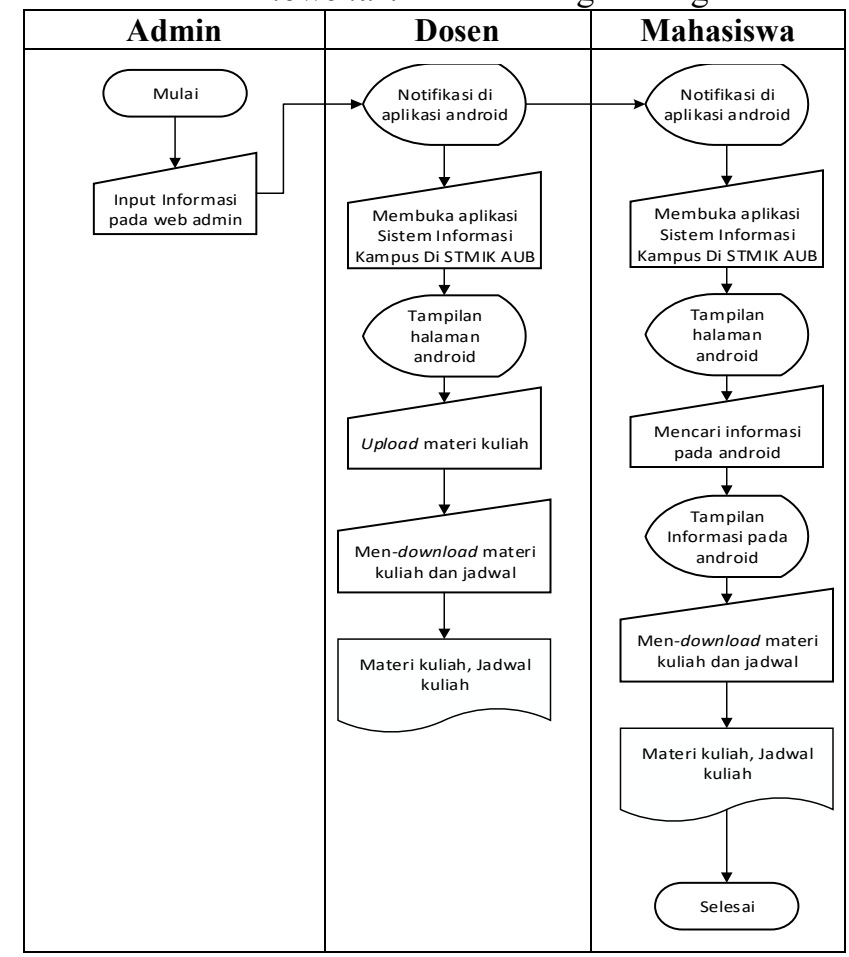

Keterangan tabel 1. Flowchart sistem yang dibangun, admin menginputkan informasi pada web admin. Ketika admin sudah menginputkan informasi, maka setiap user akan mendapatkan notifikasi untuk dapat mengecek aplikasi. Untuk setiap dosen dapat mengunggah materi kuliah di Sistem Informasi Kampus tersebut. Sedangkan bagi mahasiswa mendapatkan informasi berita terbaru, jadwal kuliah, dan dapat menngunduh materi dan jadwal.

GO INFOTECH: JURNAL ILMIAH STMIK AUB Vol. 24, No. 1, Juni 2018 : 1 - 11 


\subsection{Usecase Diagram}

Berikut Usecase Diagram Sistem Informasi Kampus Di STMIK AUB Surakarta:

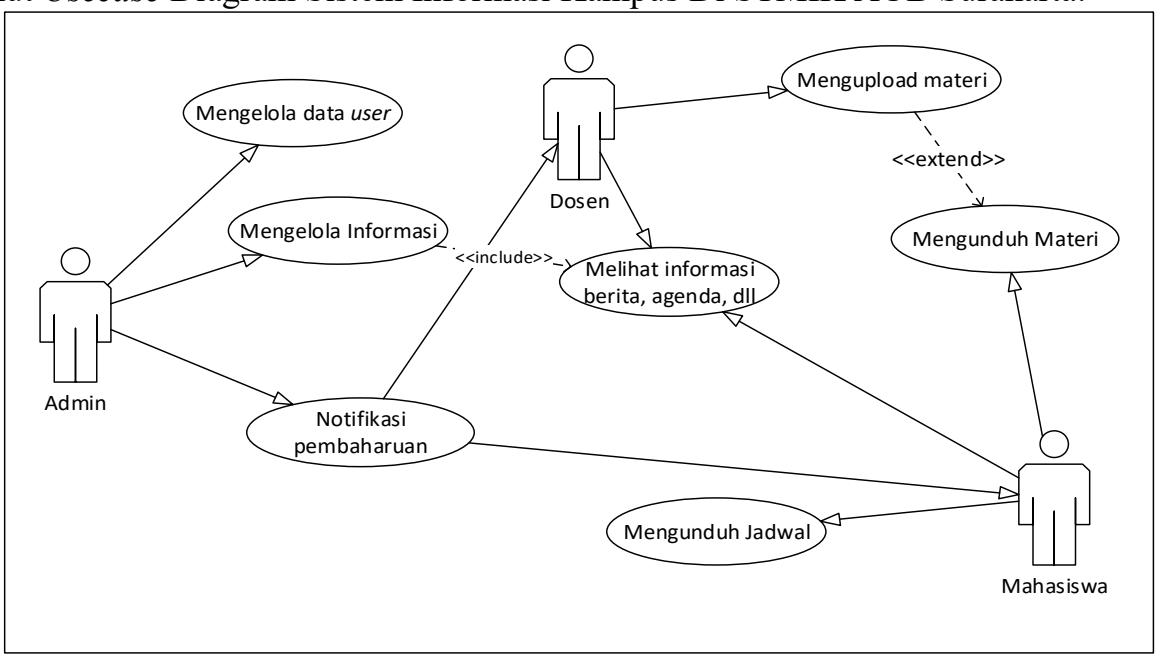

Gambar 2 Usecase Diagram Sistem Informasi Kampus

Keterangan gambar 2. Usecase Diagram Sistem Informasi Kampus adalah sebagai berikut:

Tabel 2 Actor Usecase Diagram Sistem Informasi Kampus

\begin{tabular}{|c|l|}
\hline Aktor & \multicolumn{1}{|c|}{ Keterangan } \\
\hline Admin & $\begin{array}{l}\text { Aktor admin bertugas untuk mengelola informasi dan } \\
\text { memperbarui informasi sehingga user mendapatkan } \\
\text { notifikasi pembaruan informasi }\end{array}$ \\
\hline Dosen & $\begin{array}{l}\text { Aktor dosen mendapatkan notifikasi informasi terbaru } \\
\text { serta mengupload materi kuliah. }\end{array}$ \\
\hline Mahasiswa & $\begin{array}{l}\text { Aktor mahasiswa mendapatkan notifikasi informasi } \\
\text { terbaru, mengunduh materi dan jadwal kuliah. }\end{array}$ \\
\hline
\end{tabular}

\section{HASIL DAN PEMBAHASAN}

Dalam pembuatan aplikasi Sistem Informasi Kampus ini dibutuhkan suatu implementasi untuk menguraikan program dan analisis dari hasil program yang telah dibuat. Tujuan pembahasan ini adalah untuk mengetahui apakah program yang dibuat sudah bekerja seperti yang diharapkan atau belum. Berikut adalah proses pembahasan interface atau antarmuka program:

3.1. Antar muka halaman admin berbasis web

1. Halaman Login Admin 


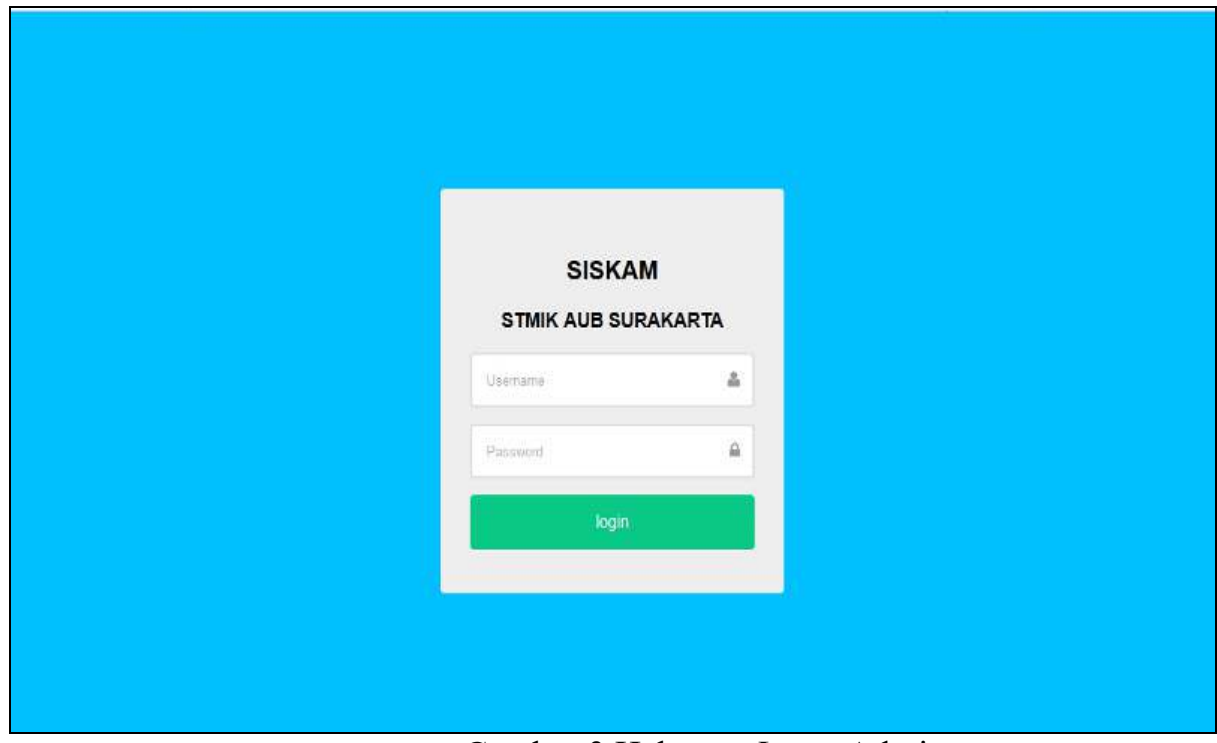

Gambar 3 Halaman Login Admin

Admin harus memasukkan username dan password lalu klik tombol login. Jika username dan password benar maka sistem akan menampilkan halaman beranda admin. Jika username dan password salah maka tidak dapat masuk pada halaman beranda admin.

2. Halaman Beranda Admin

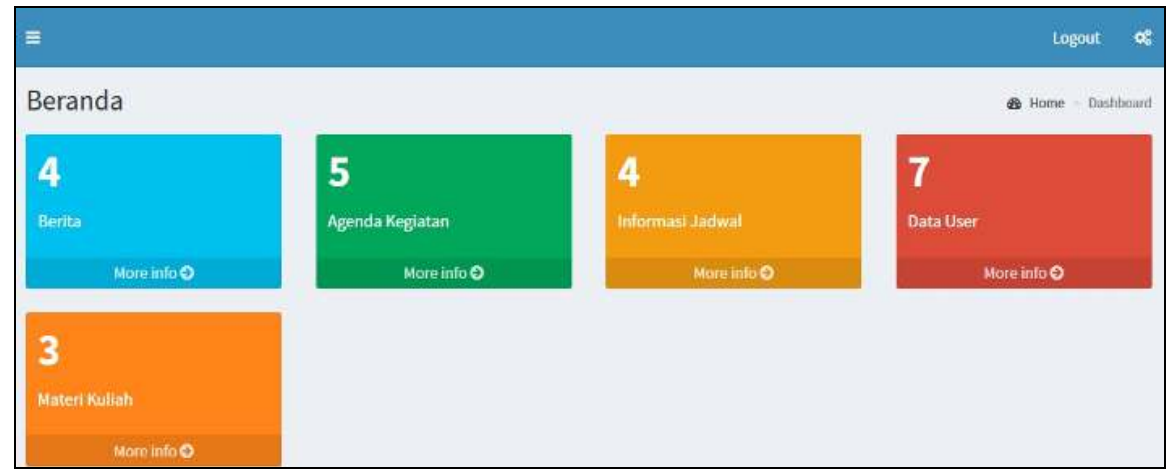

3. Halaman Data User

Gambar 4 Halaman Beranda Admin

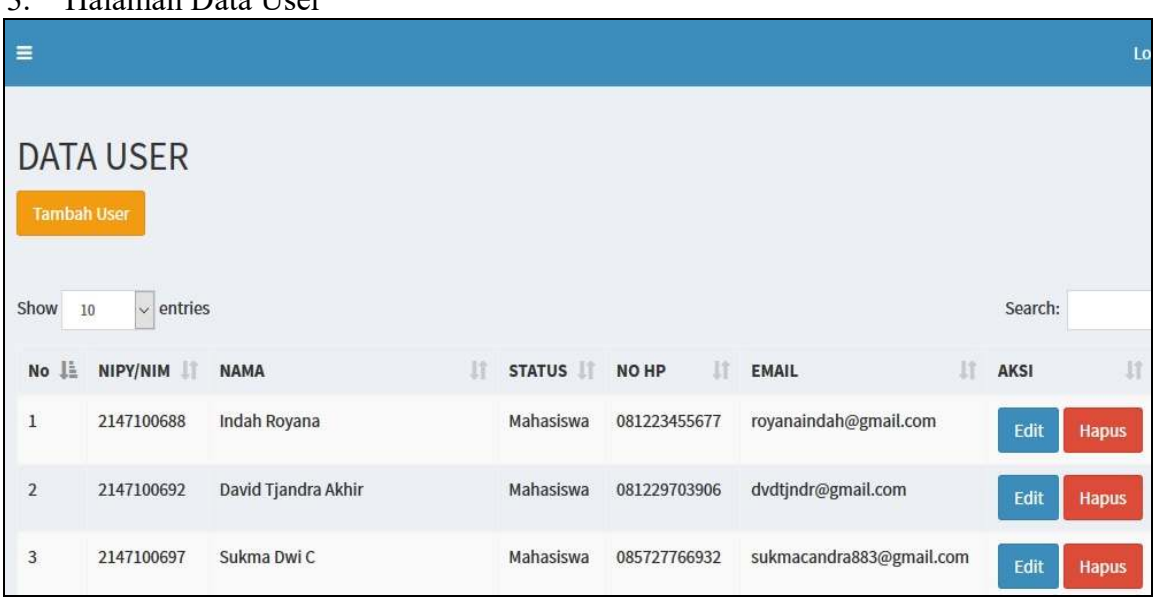

Gambar 5 Halaman Data User 
3.2. Antar Muka Halaman User Berbasis Android

1. Halaman Login User

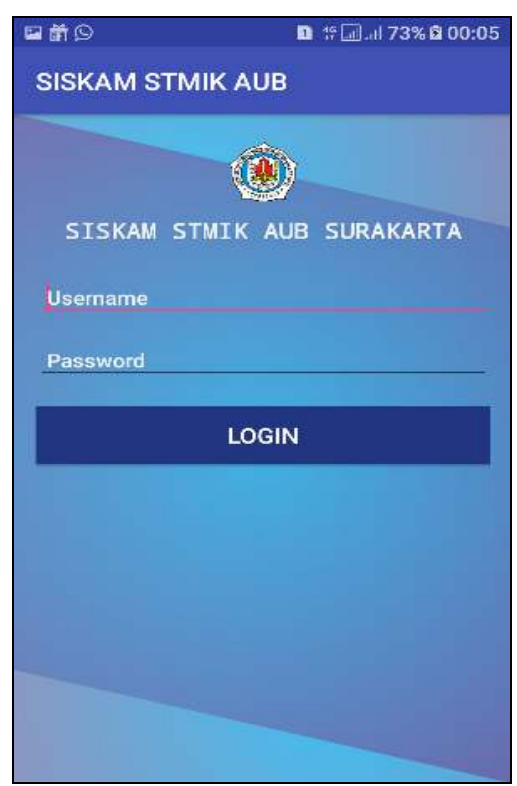

2. Halaman Update Data

Gambar 6 Halaman Login User

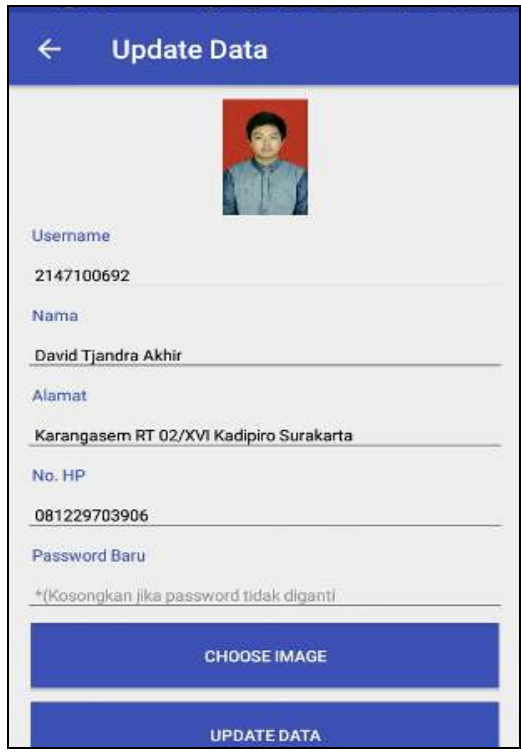

Gambar 7 Halaman Update Data

User dapat melihat dan mengubah data diri. Data tidak boleh kosong kecuali password. User dapat mengubah password atau tetap menggunakan password lama.

3. Halaman Agenda Kegiatan 
4. Halaman Detail Agenda

5. Halaman Jadwal Kuliah

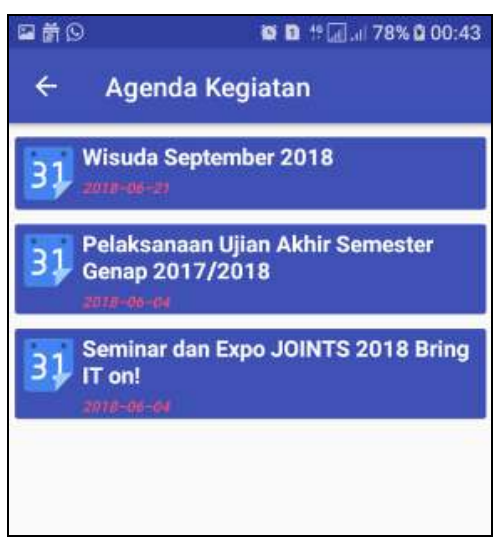

Gambar 8 Halaman Agenda Kegiatan

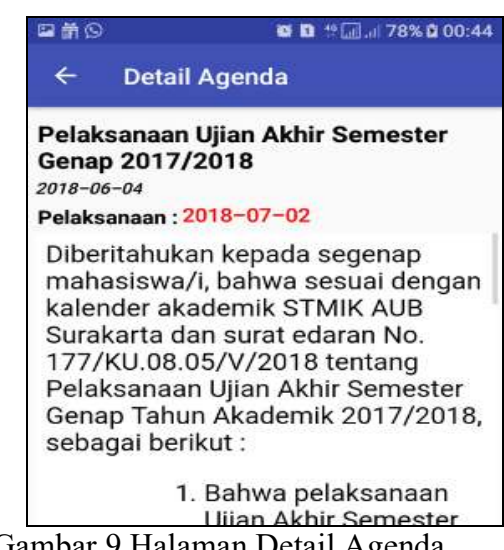

Gambar 9 Halaman Detail Agenda

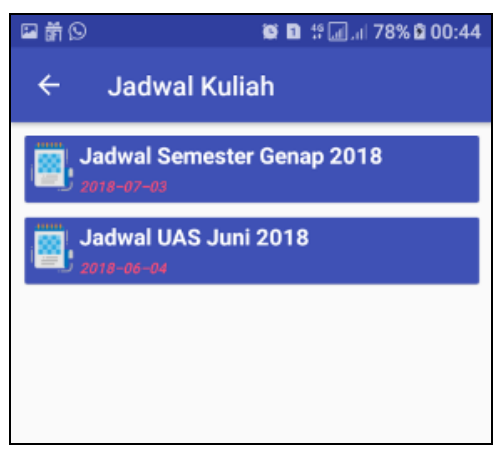

Gambar 10 Halaman Jadwal Kuliah

Dalam pembahasan sistem baru, penulis menggunakan analisis PIECES yang terdiri dari performance, information, control, efficiency dan service. Sebagai alat ukur untuk menganalisa perbandingan antara sistem lama dengan sistem yang baru, seperti berikut:

Tabel 2 Pembahasan Sistem Baru

\begin{tabular}{|l|l|l|}
\hline \multicolumn{1}{|c|}{ Analisa } & \multicolumn{1}{|c|}{ Hasil Analisis Sistem Lama } & \multicolumn{1}{c|}{ Hasil Analisis Sistem Baru } \\
\hline $\begin{array}{l}\text { Perfomance } \\
\text { (Kinerja) }\end{array}$ & $\begin{array}{l}\text { Sistem informasi yang lama } \\
\text { meskipun ada website tetapi } \\
\text { masih menggunakan media } \\
\text { kertas, dimana informasi } \\
\text { tersebut ditempelkan di papan } \\
\text { informasi. }\end{array}$ & $\begin{array}{l}\text { Sistem yang baru berbasis android, } \\
\text { namun sistem dapat berjalan baik } \\
\text { secara } \text { online. Sehingga } \\
\text { memudahkan pengguna dalam } \\
\text { mengakses aplikasi tersebut. }\end{array}$ \\
\hline
\end{tabular}

GO INFOTECH: JURNAL ILMIAH STMIK AUB Vol. 24, No. 1, Juni 2018 : 1 - 11 


\begin{tabular}{|l|l|l|}
\hline $\begin{array}{l}\text { Information } \\
\text { (nfformasi) }\end{array}$ & $\begin{array}{l}\text { Informasi yang disampaikan } \\
\text { sering terlambat diterima karena } \\
\text { mahasiswa harus mengecek } \\
\text { website atau menunggu bagian } \\
\text { akademik memberikan } \\
\text { informasi terbaru. }\end{array}$ & $\begin{array}{l}\text { Informasi yang diberikan selalu } \\
\text { tepat waktu, karena aplikasi } \\
\text { dibangun menggunakan sistem } \\
\text { notifikasi. Sehingga pengguna } \\
\text { secara langsung mendapatkan } \\
\text { informasi terbaru. }\end{array}$ \\
\hline $\begin{array}{l}\text { Economy } \\
\text { (Ekonomi) }\end{array}$ & $\begin{array}{l}\text { Sistem yang lama masih } \\
\text { menggunakan cara manual } \\
\text { untuk memberikan informasi } \\
\text { meskipun terdapat } \text { website, } \\
\text { sehingga membuang waktu } \\
\text { datang ke kampus untuk } \\
\text { sekedar melihat informasi. }\end{array}$ & $\begin{array}{l}\text { Hampir seluruh mahasiswa dan } \\
\text { dosen memiliki handphone android, } \\
\text { sehingga dapat menjalankan } \\
\text { aplikasi di handphone masing- } \\
\text { masing dimanapun dan kapanpun } \\
\text { sekalipun tidak berada di } \\
\text { lingkungan STMIK AUB } \\
\text { Surakarta. }\end{array}$ \\
\hline $\begin{array}{l}\text { Control } \\
\text { (Keamanan) }\end{array}$ & $\begin{array}{l}\text { Keamanan kurang karena } \\
\text { beberapa informasi masih } \\
\text { menggunakan kertas yang } \\
\text { ditempel di papan pengumuman. }\end{array}$ & $\begin{array}{l}\text { Keamanan lebih terjamin karena } \\
\text { aplikasi berbentuk file apk, selain } \\
\text { itu setiap akun hanya bisa login } \\
\text { menggunakan } \text { username dan } \\
\text { password yang disediakan oleh } \\
\text { admin. }\end{array}$ \\
\hline $\begin{array}{l}\text { Service } \\
\text { Layanan) }\end{array}$ & $\begin{array}{l}\text { Pelayanan hanya satu arah, } \\
\text { bagian akademik harus } \\
\text { menyiapkan atau mencetak } \\
\text { informasi yang harus } \\
\text { ditempelkan di papan } \\
\text { pengumuman. }\end{array}$ & $\begin{array}{l}\text { Pelayanan yang diberikan pada } \\
\text { aplikasi cukup membantu } \\
\text { pengguna, karena memudahkan } \\
\text { mahasiswa untuk mendapatkan } \\
\text { informasi. }\end{array}$ \\
\hline $\begin{array}{l}\text { Efficiency } \\
\text { Efisiensi) }\end{array}$ & $\begin{array}{l}\text { Belum efisien, karena sudah ada } \\
\text { pengan manual atau dengan }\end{array}$ & $\begin{array}{l}\text { Sudah efisien, karena di dalam } \\
\text { aplikasi sudah dilengkapi dengan } \\
\text { informasi kampus, jadwal } \\
\text { perkuliahan dan materi perkuliahan. } \\
\text { Sehingga pengguna dengan mudah } \\
\text { mendapatkan informasi. }\end{array}$ \\
\hline
\end{tabular}

\section{KESIMPULAN}

Kesimpulan dari aplikasi Sistem Informasi Kampus Di STMIK AUB Surakarta yang dirancang dan dibuat, yaitu:

a. Pada perancangan sistem menggunakan metode pengumpulan data yaitu metode wawancara, observasi, dan studi pustaka yang menggunakan sumber data primer dan data sekunder. Untuk metode perancangan sistem menggunakan Flowchart, UML (Unified Modeling Language) yang tediri dari Usecase Diagram, Activity Diagram, Sequence Diagram, Class Diagram, dan Entity Relationship Diagram. Sedangkan untuk metode pengembangan sistem menggunakan metode Waterfall. Hasil dari perancangan sistem yaitu Sistem Informasi Kampus Di STMIK AUB Surakarta.

b. Pengembangan sistem menggunakan bahasa pemrograman Java, tool yang digunakan yaitu Android Studio Versi 3.0.1, pada website menggunakan bahasa pemrograman PHP, dan MySQL sebagai database. Sistem ini bisa melakukan pengolahan data berita, agenda, jadwal dan materi kuliah. 
Adanya Sistem Informasi Kampus Di STMIK AUB Surakarta memberikan media baru bagi mahasiswa dan dosen dalam menyediakan informasi. Selain itu juga sistem informasi kampus dilengkapi dengan berita seputar kampus yang dapat memberikan informasi berita bagi mahasiswa dan dosen. Agenda kegiatan kampus yaitu informasi kegiatan yang akan dilaksanakan di kampus. Jadwal perkuliahan berupa file format pdf yang dapat di-download serta materi kuliah berupa file format pdf yang di-upload oleh dosen dan kemudian dapat didownload oleh mahasiswa. Hasil dari penelitian ini adalah membuat suatu aplikasi sistem informasi kampus berbasis android yang dapat membantu dosen dalam membagikan materi perkuliahan dan membantu mahasiswa untuk mendapatkan informasi secara detail dan cepat.

\section{SARAN}

Aplikasi Sistem Informasi Kampus Di STMIK AUB Surakarta ini masih dapat dikembangkan lebih lanjut, yaitu:

a. Menambahkan sistem informasi akademik agar mahasiswa dapat mengakses pembayaran dan dapat mengakses KRS ataupun KHS.

b. Menambahkan sistem informasi presensi agar dosen dan mahasiswa dapat melakukan presensi dengan mudah hanya dengan menggunakan aplikasi android.

c. Menambahkan informasi tentang akreditasi program studi/institusi.

d. Menambahkan informasi komentar, kritik dan saran sehingga jika terjadi kesalahan informasi, user dapat memberikan komentar, kritik dan saran pada admin.

\section{DAFTAR PUSTAKA}

[1] Christian, Yohanes. 2015. Perancangan Sistem Informasi Akademik Pada Akademi Keperawatan Adi Husada. Jurnal Ilmiah Mahasiswa Universitas Surabaya Vol.4 No. 2.

[2] Fiska, Ayu. 2009. Sistem Informasi Akademik Universitas Surakarta Berbasis Web. Journal Speed - Sentra Penelitian Engineering dan Edukasi, Vol. 1 No. 1, Universitas Surakarta.

[3] Gata, Windu. 2016. Pemodelan UML Sistem Informasi Monitoring Penjualan Dan Stok Barang (Studi Kasus: Distro Zhezha Pontianak). Jurnal Khatulistiwa Informatika, Vol. IV, No. 2 Desember 2016.

[4] Irawan, Dedi. 2012. Perancangan Sistem Informasi Akademik Berbasis Web Pada Program Studi Diploma III Manajemen Informatika UM Metro Lampung. Jurnal Informatika, Vol. 12 No. 2, Desember 2012, UM Metro Lampung.

[5] Jogiyanto, H. 2005. Analisis dan Desain Sistem Informasi. Yogyakarta: Andi Offset.

[6] Json. 2018. Pengenalan Json. https://www.json.org/json-id.html diakses pada 5 Maret 2018.

[7] Khasanah, Asli Khatul. 2015. Pengembangan Dan Analisis Kualitas Berdasarkan Iso 9126 Aplikasi Pendeteksi Gaya Belajar Model Vak (Visual, Auditorial, Kinestetik) Berbasis Web. Universitas Negeri Yogyakarta.

[8] Kustiyahningsih, Y \& Anamisa, D. 2011. Pemrograman Basis Data Berbasis Web Menggunakan PHP \& MySql. Yogyakarta: GRAHA ILMU.

[9] Lenti, Febri. 2014. Rekayasa Database Terdistribusi Pada Layanan Pemesanan Tiket Pesawat Terbang. Jurnal Teknologi Technoscientia - ISSN: 1979-8415, Vol. 6 No. 2, STMIK AKAKOM Yogyakarta.

[10] Maulana, A. 2015. Belajar Membuat Aplikasi di Android Studio. Diakses pada 1 Maret 2018, dari http://www.teknologiterbaru.tk/2015/06/belajar-membuat-aplikasi-di-androidsudio.html

[11] Murtiwiyati \& Lauren. 2013. Rancang Bangun Aplikasi Pembelajaran Budaya Indonesia Untuk Anak Sekolah Dasar Berbasis Android. Jurnal Ilmiah Komputasi - ISSN: 14129434, Vol. 12, No. 2, Jakarta.

GO INFOTECH: JURNAL ILMIAH STMIK AUB Vol. 24, No. 1, Juni 2018 : 1 - 11 
[12] Pressman, Roger. 2012. Rekayasa Perangkat Lunak. Buku Satu, Pendekatan Praktisi (Edisi 7). Yogyakarta.

[13] Rahayu, Minto. 2007. Bahasa Indonesia Di Perguruan Tinggi. Jakarta: Grafindo.

[14] Rizki, Muhammad. 2016. Sistem Informasi Akademik Berbasis Web Di SMP Negeri 2 Kecamatan Gaung Anak Serka. Jurnal Sistemasi - ISSN: 2302-8149, Vol. 5, No. 3, Riau.

[15] Setiabudi, Budijanto \& Andjarwirawan. 2012. Sistem Informasi Akademik: Studi Kasus Pada SMP Gracia. Laporan Penelitian - NO: 124/Pen/Informatika/IX/2012. Fakultas Teknologi Industri Universitas Kristen Petra: Surabaya.

[16] Supriyatna, Adi. 2015. Analisis Dan Evaluasi Kepuasan Pengguna sistem Informasi Perpustakaan dengan menggunakan PIECES Framework. Jurnal Pilar Mandiri - ISSN: 1978-1946, Vol. XI, No. 1, AMIK BSI, Karawang.

[17] Usman, Husnaini \& Akbar. 2000. Metodologi Penelitian Sosial. Jakarta: PT. Bumi Aksara. 